\section{Geographical restriction of Hepatitis $E$ virus circulation in wild boars (Sus scrofa) in Emilia-Romagna region, Northern Italy}

\author{
Silvia Bonardi, ${ }^{1}$ Virginia Filipello, ${ }^{2}$ \\ Enrico Pavoni, ${ }^{2}$ Valentina Carta, ${ }^{2}$ \\ Luca Bolzoni, ${ }^{3}$ Margherita Corradi, ${ }^{4}$ \\ Stefano Gilioli, ${ }^{4}$ Marina Nadia Losio ${ }^{2}$
}

${ }^{1}$ Department of Veterinary Science, Unit of Food Inspection, University of Parma; ${ }^{2}$ Istituto Zooprofilattico

Sperimentale della Lombardia e dell'Emilia-Romagna (IZSLER), Section of Brescia; ${ }^{3}$ Istituto Zooprofilattico Sperimentale della Lombardia e dell'Emilia-Romagna (IZSLER), Risk Analysis and Genomic Epidemiology Unit, Parma; ${ }^{4}$ Management Body for Parks and Biodiversity "Emilia Occidentale", Sala Baganza, Italy

\section{Abstract}

Hepatitis E virus (HEV) is a singlestrand RNA virus that causes an acute viral hepatitis in humans. Among its eight recognized genotypes, HEV-3 and HEV-4 are zoonotic, infecting humans, pigs and wild boars. Recently, HEV-3 has been also detected in red deer, which represents another reservoir of HEV. Consumption of raw pork products (mainly liver sausages), undercooked wild boar meat, raw wild boar liver and deer meat has been responsible for foodborne HEV human worldwide. From November 2018 to March 2019, liver samples collected from 97 wild boars hunted in Emilia-Romagna region (Northern Italy) were tested for HEV RNA. The hunting area included two territories for an extension of $33 \mathrm{~km}^{2}$, named A (about $13 \mathrm{~km}^{2}$, natural park, deciduous wood) and $\mathrm{B}$ (about $20 \mathrm{~km}^{2}$, cultivated fields in proximity of a river) areas. Distance between the two areas ranged between 8 to $10 \mathrm{~km}$. A total of 73 wild boars were hunted in area A, and 24 in area B. HEV RNA was detected by Real-time RTPCR in 23/73 liver samples of wild boars living in area A only $(31.5 \%-95 \%$ CI: $22.0-$ $42.8 \%)$. The HEV sequences $(n=13)$ clustered within genotype 3 . The majority of positives belonged to animals $<12$ months $(12 / 25 ; 48 \%)$, followed by subadults (13-24 months) $(7 / 16 ; 43.8 \%)$ and adults $(4 / 32$; $12.5 \%$ ). This difference was found to be statistically significant $(\mathrm{p}=0.0024)$. In absence of pig farms, the restriction of HEV-positive animals to a well-defined territory of $13 \mathrm{~km}^{2}$ (Boschi di Carrega Regional Park) could hypothetically be related to the presence of red deer (Cervus elaphus), which lived in area $\mathrm{A}$ at the beginning of the hunting season. Further studies are needed to confirm or deny our hypothesis.

\section{Introduction}

Hepatitis E virus (HEV) is a singlestrand RNA virus that in humans causes an acute viral hepatitis after an incubation period of 4-5 weeks, but the infection is often asymptomatic. However, even if the mortality rate is generally low $(0.5 \%)$, it can reach $25 \%$ in pregnant women (Farshadpour et al., 2018). HEV is divided in into eight recognized genotypes. HEV-1 and HEV-2 are restricted to humans and circulate in developing countries, where they are endemic, causing outbreaks linked to contaminated water (Doceul et al., 2016). HEV-3 and HEV-4 are zoonotic, infecting humans and animal species among which pigs and wild boars are the main reservoirs. Over the last 10 years, HEV-3 and HEV-4 human infections have been observed increasingly in industrialized countries linked commonly to the consumption of raw pork products (mainly liver sausages) but also undercooked wild boar meat (Pavio et al., 2017). Concerning the role of wildlife animals in the zoonotic transmission of HEV, the first evidence was derived from cases of human HEV infection due to consumption of sika deer (Cervus nippon) and wild boar meat (Tei et al., 2003; Sonoda et al., 2004).The more recent genotypes are HEV-5 and HEV-6 detected in Japanese wild boars, and HEV-7 and HEV-8 detected in camels (Sridhar et al., 2017). The survival of HEV in the environment has been reported in several studies, in particular Johne et al. (2016) demonstrated that HEV particles remain infective after one month at room temperature and after more than 2 months at $4^{\circ} \mathrm{C}$. In pigs, the virus is mainly excreted in feces, leading to an accumulation of HEV in the environment that is pivotal for the spread of infection (Andraud et al., 2013). In this perspective, HEV contamination of water or the environment in the vicinity of pig farms, especially around slurry storage facilities, may persist for a long time and may represent a transmission route for the wild fauna (Kasorndorkbua et al., 2005).

Among consumers, hunters are particularly exposed to foodborne hepatitis $\mathrm{E}$, if they are used to eat undercooked wild boar meat (Rivero-Juarez et al., 2017). In order to minimize the risk of $\mathrm{HEV}$ infection, especially vulnerable groups of consumers
Correspondence: Silvia Bonardi, Department of Veterinary Science, University of Parma, Strada del Taglio 10, 43126, Parma, Italy.

Tel.: +39.0521.032744.

E-mail: silvia.bonardi@unipr.it

Key words: Hepatitis E virus, Wild boars, Italy.

Conflict of interests: The authors declare no potential conflict of interests.

Contributions: the authors contributed equally.

Funding: The study was funded by the Italian Ministry of Health.

Availability of data and materials: The data that support the findings of this study are available from the corresponding author upon reasonable request.

Ethics approval and consent to participate: This research was conducted in accordance with all relevant guidelines and procedures.

Consent for publication: The manuscript does not contain any individual person's data in any form.

Received for publication: 2 August 2019. Revision received: 2 December 2019.

Accepted for publication: 3 December 2019.

This work is licensed under a Creative Commons Attribution-NonCommercial 4.0 International License (CC BY-NC 4.0).

(C) Copyright: the Author(s), 2020

Licensee PAGEPress, Italy

Italian Journal of Food Safety 2020; 9:8463

doi:10.4081/ijfs.2020.8463

(e.g. persons with a weakened immune system or with pre-existing liver injury) should thoroughly cook meat, liver and meat products derived from wild boars, pigs and red deer, ensuring a minimum internal temperature of $71^{\circ} \mathrm{C}$ for $20 \mathrm{~min}$ (EFSA, 2017).

In Italy, HEV-3 and HEV-4 have been described mainly in pigs, with one human case linked to HEV-4 (Garbuglia et al., 2013). HEV prevalence in wild boar is variable, partly due to regional differences but also due to the variety of specimens tested and methods applied (Caruso et al., 2017; De Sabato et al., 2018a) that hamper comparison between studies. The role of wild fauna and the implications for diffusion dynamics remain therefore unclear. The aim of this study was to investigate the occurrence of HEV in livers collected from wild boars hunted in Italy and destined to human consumption. The animals were hunted under depopulation programs in force in Emilia-Romagna region, Northern Italy. 
Bio-Rad CFX96 system (Bio-Rad, Hercules, CA, USA) with the thermal profile and reaction mix described by $\mathrm{Di}$ Pasquale et al. (2019). Mengovirus amplification was carried out as described in ISO 15216-1:2017 (ISO, 2017).

\section{Genotyping}

To determine HEV genotype a fragment of the ORF1 region of the viral genome was sequenced using the primers described by Wenzel et al. (2011). The obtained sequences were aligned with reference strains reported in literature and retrieved on the NCBI Nucleotide database (https://www.ncbi.nlm.nih.gov/nucleotide/) (Sridhar et al., 2017).

\section{Statistical analysis}

We assessed the probability of freedom from HEV in the HEV-negative area assuming as design prevalence that one estimated in the HEV-positive area. Since the wild boar population size is unknown, the calculation was based on the binomial distribution function.

In addition, we assessed through logistic regressions whether a significant difference in the detection of HEV was observed in wild boar sampled in the HEV-positive area as a function of sex and age. Specifically, to test the effect of age, we introduced the ordinal explanatory variable age group, where the sampled animals were subdivided in three age classes: young, subadults, and adults. The ordinal variable age group was included in the model using orthogonal polynomials (Chihara, 1978). Orthogonal polynomials represent a useful tool to take in to account in regression models for the linear and higher degree effects of ordinal explanatory variables on the response variable. For variables with $k$ ordered levels, orthogonal polynomials with degrees from 1 to $k-1$ can be used. Since age group is characterized by three ordinal levels, orthogonal polynomials with degrees 1 (representing the linear effect of the age group) and 2 (representing the quadratic effect of age group) were tested. Moreover, for female individuals only, we tested through logistic regression whether the detection of HEV was significantly affected by the pregnancy status in addition to the age group. The models providing the best prediction were assessed through loglikelihood ratio tests (Venables and Ripley 2002). We used the odds ratio (OR) as effect-size statistics in logistic regressions.

arated by inhabited areas and a high-speed road; in addition, some traits of area A are surrounded by fences. Neither pig farms, nor backyard swine are present in the study areas. A portion of the liver (50 g approximately) was collected from each animal, stored in sterile containers and frozen at $20^{\circ} \mathrm{C}$ until use. Only animals dead less than 5 hours were included in the study. Gender, pregnancy status and age of the animals were recorded. The age was determined based on tooth eruption (Saez-Royuela et al., 1989); the animals were considered "young" (class 0) when $\leq 12$-month-old, "sub-adults" (class 1) when 13-24 monthold and "adults" (class 2) when >24 monthold.

\section{RNA extraction and purification}

For each liver sample $450 \mathrm{mg}$ were homogenized with QIAzol Lysis Reagent (Qiagen, Hilden, Germany) according to producer instructions and spiked with $10 \mu \mathrm{L}$ of a titrated suspension of Mengovirus process control $\left(1.6 \times 10^{5}\right.$ TCID50 per ml; strain $\mathrm{MC0}$ ). RNA has then been purified with the NucliSENS $\AA$ MiniMag Kit (bioMérieux, Marcy-l'Étoile, Francia). The eluted RNA was conserved at $-80^{\circ} \mathrm{C}$ until use.

\section{One-Step Real-time RT-PCR detec- tion of HEV}

HEV RNA was detected using a OneStep real-time RT-PCR based on the primers and probe described by Jothikumar et al. (2006). All PCRs were executed on a

Figure 1. The hunting areas in Parma province, Emilia-Romagna region, Northern Italy. Area $\mathrm{A}$ has an extension of about $13 \mathrm{~km}^{2}$ (deciduous wood; Boschi di Carrega Regional Park). Area B has an extension of about $20 \mathrm{~km}^{2}$ (both cultivated and bushy areas in the proximity of the river Taro).

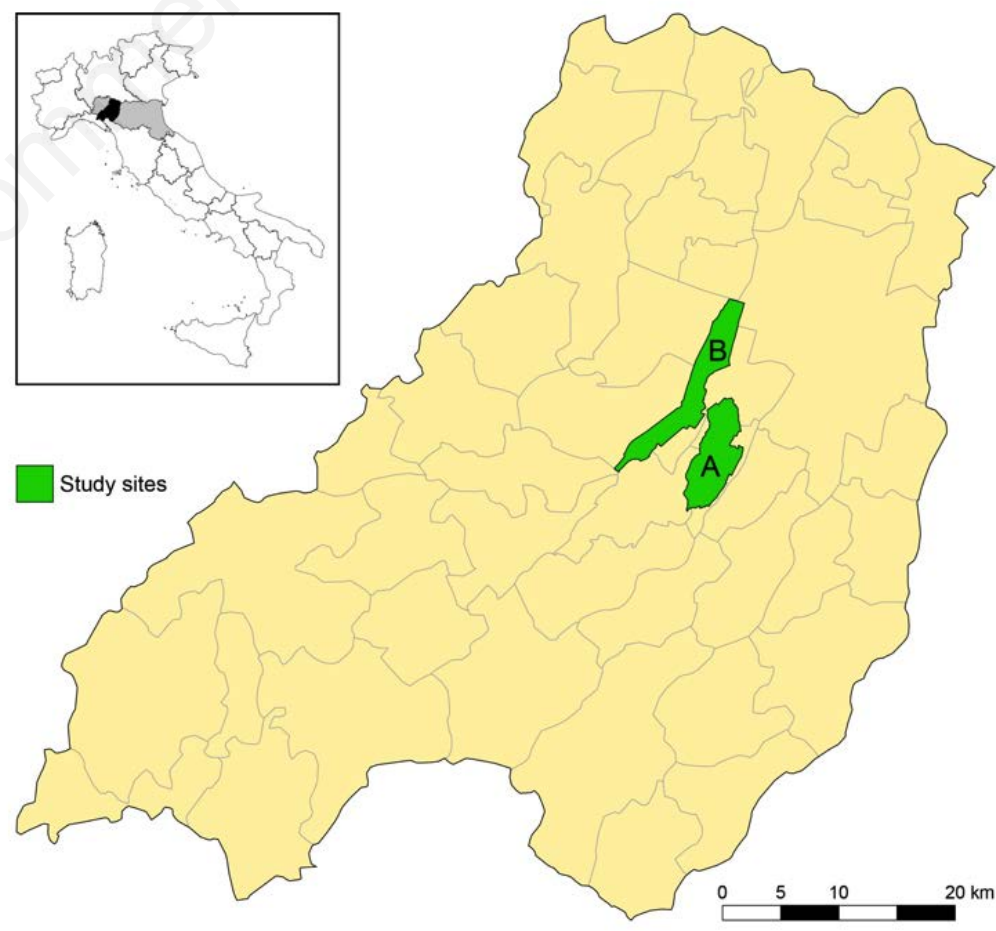




\section{Results}

Age, gender and pregnancy status of sampled animals in the two areas are reported in Table 1. HEV was detected in 23/73 wild boar livers sampled in area A (apparent prevalence $31.5 \%$ - 95\% CI: $22.0-42.8 \%$ ) (Table 2) and was not detected in the 24 wild boar livers sampled in area B. Genotype was determined for 13 strains that shared $99.99 \%$ identity and corresponded to HEV-3. The probability of freedom from HEV in area B, estimated through binomial distribution function, was highly significant $\left(\mathrm{p}_{\text {free }}=0.99989\right)$.

Among age groups, the majority of positives in the infected area belonged to the young age group $(12 / 25 ; 48 \%)$, followed by the sub-adult $(7 / 16 ; 43.8 \%)$ and adult age groups $(4 / 32 ; 12.5 \%)$. The logistic regression models with degree- 1 and degree-2 orthogonal polynomials showed a significantly linear decrease in HEV detection with the age group $(\mathrm{OR}=0.37$; CI95\% $=$ 0.19-0.68), while quadratic effects were not observed $(\mathrm{OR}=0.71 ; \mathrm{CI} 95 \%=0.24-1.95)$.
Moreover, we did not find any significant relationships between animal gender and HEV detection both in the univariable logistic regression $(\mathrm{OR}=0.87$; CI95\% $=0.25$ 2.77) and in the multivariable regression including age and $\operatorname{sex}(\mathrm{OR}=0.55$; CI95\% $=$ $0.13-1.94)$. The results of the model selection were summarized in Table 3. Analogously, we did not find any significant relationships between the pregnancy status of female individuals and HEV detection both in the univariable logistic regression $(\mathrm{OR}=0.37$; CI95\% $=0.11-1.16)$ and in the multivariable regression including age and pregnancy status $(\mathrm{OR}=1.44$; CI95\% $=$ $0.30-8.77)$.

\section{Discussion}

Since Suidae are considered the main animal reservoir of HEV worldwide (Pavio et al., 2017), in Italy as well as in other EU countries pigs and wild boars have been frequently tested to shed light on this important zoonosis. In Italy, HEV-3 has been pre- viously described in pigs as well as in wild boars (Di Bartolo et al., 2008; Caruso et al., 2015), in pork products (Di Bartolo et al., 2012, 2015) and in autochthonous, not travel-related human cases of hepatitis E (Romanò et al., 2011). Reports from EU countries largely confirm the role of pigs and wild boars in the epidemiology of HEV infection (Berto et al., 2012; Kukielka et al., 2016; Porea et al.2018; Spancerniene et al., 2018; Wenzel et al., 2011).

In accordance with the infectious dynamics in pigs, whose HEV faecal shedding period corresponds mainly to $3-4$ months of age and decreases after 6 months of age (Salines et al., 2017), the majority of HEV-positive wild boars tested in this study belonged to class 0 ( $\leq 12$ months). The statistical analyses showed that the detection of HEV RNA significantly decrease with animal age, thus suggesting that the immunity status due to previous contacts with HEV was effective against re-infections. On the contrary, neither gender nor pregnancy status influenced HEV infection status in the wild boar population tested.

Table 1. Distribution of the wild boars in the two hunting areas by gender, pregnancy status, and age class. Age class legend: Young (<12 months), Sub-adults (13-24 months), and Adults ( $>24$ months).

\begin{tabular}{llcccc}
\hline Area & Gender & Young & Age class & Total \\
& & Sub-adults & Adults & 18 \\
A & Male & 9 & 3 & 4 & $55(29)$ \\
& Female (No. pregnant) & $16(1)$ & $13(11)$ & $28(17)$ & 14 \\
B & Male & 6 & 1 & 7 & $10(6)$ \\
& Female (No. pregnant) & $4(1)$ & $1(1)$ & $5(4)$ & $97(35)$ \\
\hline Total & & $35(2)$ & $18(12)$ & $44(21)$ & \\
\hline
\end{tabular}

Table 2. Prevalence of HEV-positive liver samples of wild boars of different age groups in area A.

\begin{tabular}{lcccc} 
Age class & $\begin{array}{c}\text { No. of animals in the whole } \\
\text { teritory (M/F) }\end{array}$ & $\begin{array}{c}\text { No. of animals in area } \\
\mathbf{A}(\mathbf{M} / \mathbf{F})\end{array}$ & $\begin{array}{c}\text { No. of positives in area A } \\
(\mathbf{M} / \mathbf{F})\end{array}$ & $\begin{array}{c}\text { Prevalence among age classes } \\
\text { in area } \mathbf{A}, \%\end{array}$ \\
Young & $35(15 / 20)$ & $25(9 / 16)$ & $12(3 / 9)$ & 48.0 \\
Sub-adults & $18(4 / 14)$ & $16(3 / 13)$ & $7(1 / 6)$ & 43.8 \\
Adults & $44(11 / 33)$ & $32(4 / 28)$ & $4(2 / 2)$ & 12.5 \\
Total & $97(30 / 67)$ & $73(16 / 57)$ & $23(6 / 17)$ & 31.5 \\
\hline
\end{tabular}

M: males; F: females.

Table 3. Model selection for HEV occurrence in wild boar livers sampled in area A obtained from logistic regressions. Models were compared using log-likelihood ratio test. The models with Df degree of freedom are shown, with the log-likelihood (loglik), and the p-value of the comparison with the "Df -1 " best model.

\begin{tabular}{|c|c|c|c|}
\hline Model & loglik & $D f$ & p \\
\hline$\sim 1^{(\mathrm{a})}$ & -45.49 & 1 & - \\
\hline$\sim \operatorname{sex}$ & -45.46 & 1 & 0.83 \\
\hline$\sim$ age degree-1(b) & -40.18 & 2 & 0.0011 \\
\hline$\sim$ age degree-1 + age degree-2(c) & -39.95 & 3 & 0.49 \\
\hline$\sim$ age degree-1 + sex & -39.71 & 3 & 0.33 \\
\hline
\end{tabular}

aNull model; bdegrees-1 orthogonal polynomial; cdegrees-2 orthogonal polynomial. 
In our study, HEV-3-positive animals were confined to a well-defined territory of $13 \mathrm{~km}^{2}$, i.e the Boschi di Carrega Regional Park (Parma province), characterized by the absence of pig farms as well as backyard swine. In Parma province, pigs are commonly reared following strict biosecurity procedures, in accordance with Parma Ham Consortium guidelines and third countries export requirements. Direct contact between domestic and feral pigs is therefore to exclude, such as between pig farm personnel/equipment and wild boars. On the contrary, indirect contact between pigs and wild boars could not be completely excluded, favoured by the use of pig manure in agriculture and the consequent dispersion of virus particles in large cultivated areas. However, the appropriate treatment of manure required for intensive pig farming procedures reduces the risk of environmental pollution and indirect contact between farmed and feral pigs. Interestingly, at the very beginning of the hunting season (October 2018), a wintry familiar group of red deer (Cervus elaphus) composed of about 13 animals (female adults, female sub-adults and young deer) was living in the park. HEV infection has been recently demonstrated in red deer in Italy. For example, a free-living red deer population was found to be positive for HEV RNA and HEV antibodies in $11.0 \%$ and $13.9 \%$ of 251 serum samples, respectively, and HEV subgenotype $3 \mathrm{e}$ could be identified in a subset of sera (Di Bartolo et al., 2017). The deer strains showed $90.0 \%$ and $91.5 \%$ nucleotide identity with human (Romanò et al., 2011) and porcine strains previously identified in the country (Di Bartolo et al., 2017). In other countries, recent surveys have detected HEV RNA or HEV antibodies in samples from wild boars and red deer collected in the same geographical areas, such as in the Netherlands (Rutjes et al., 2010), Spain (Kukielka et al., 2016) and Lithuania (Spancerniene et al., 2018), thus confirming the epidemiological role of red deer in the maintenance of HEV infection among wildlife.

In Italy, recent surveys have confirmed the role of wild boars as carriers of HEV. In different regions of the country, wild boars were found to be infected by HEV-3 subtype 3a (Di Pasquale et al., 2019), as well as subtypes 3e and 3f (Caruso et al., 2015), subtypes 3e, 3c and 3f (Serracca et al., 2015), subtypes 3c and $3 f$ (De Sabato et al., 2018a) and the novel subtype 3i, never identified before either in wild boars or in pigs (De Sabato et al., 2018b). The zoonotic potential of HEV-3 strains isolated from wild boars and showing high similarity with human HEV sequences has been demon- strated in Tuscany region, Central Italy, following a case of human infection in a municipality bordering a wild boar hunting area (Mazzei et al., 2015).

\section{Conclusions}

In Europe, HEV is endemic but the burden of the disease for humans is still unknown because the disease is not under EU surveillance. To better monitor epidemiology and human exposure to HEV, the collation of HEV data from human and animal populations from different countries would be crucial and serve the "One Health" approach to protecting human health (Adlhoch et al., 2016). The present study confirms the role of wild boars as reservoir of HEV-3 in Northern Italy, in accordance with previous data (Caruso et al., 2015; De Sabato et al., 2018a). Nevertheless, a suggestive hypothesis on the epidemiology of HEV infection in wild game can be formulated. In fact, considering the characteristics of industrial pig farming in Parma province, the infection status of the HEV-positive wild boars could be related to recent contacts with red deer. Our hypothesis is supported by the following circumstances: $i)$ the presence of red deer in the same restricted geographical area at the beginning of the hunting season; ii) the resistance of HEV in the environment (Johne et al., 2016), thus favouring its transmission to animals not living in close contact but sharing the same pasture areas; iii) the circulation of HEV-3 among red deer in Italy (Di Bartolo et al., 2017); v) the absence of free-range pig farms in the area; iv) the segregation of neighbouring domestic pigs in intensive farms characterised by high biosecurity measures. To confirm or deny our hypothesis, future studies involving HEV testing of red deer samples should be carried out.

In Italy, the role of pigs in the transmission of HEV to wild boars has been suggested (Caruso et al., 2015), but in areas where pigs are strictly segregated from wild game the epidemiological situation involving other animal populations should be investigated. In shared habitats, interspecies transmission of HEV-3 between wild boars and red deer might occur and involve humans via zoonotic/foodborne routes (Di Bartolo et al., 2017). Since hunters are the consumers at higher risk of HEV foodborne infection, more information should be supplied to this category by the competent authorities at EU level. In addition, more information on the effectiveness of different cooking practice in the mitigation of $\mathrm{HEV}$ foodborne infection should be accessible to all consumers.

\section{References}

Adlhoch C, Avellon A, Baylis SA, Ciccaglione AR, Couturier E, de Sousa R, Epštein J, Ethelberg S, Faber M, Fehér Á, Ijaz S, Lange H, Mand'áková Z, Mellou K, Mozalevskis A, Rimhanen-Finne R, Rizzi V, Said B, Sundqvist L, Thornton L, Tosti ME, van Pelt W, Aspinall E, Domanovic D, Severi E, Takkinen J, Dalton HR, 2016. Hepatitis E virus: Assessment of the epidemiological situation in humans in Europe, 2014/15. J Clin Virol 82:9-16.

Andraud M, Dumarest M, Cariolet R, Aylaj B, Barnaud E, Eono F, Pavio N, Rose N, 2013. Direct contact and environmental contaminations are responsible for $\mathrm{HEV}$ transmission in pigs. Vet Res 44:102.

Berto A, Backer JA, Mesquita JR, Nascimento MS, Banks M, Martelli F, Ostanello F, Angeloni G, Di Bartolo I, Ruggeri FM, Vasickova P, DiezValcarce M, Hernandez M, RodriguezLazaro D, van der Poel WH, 2012. Prevalence and transmission of hepatitis E virus in domestic swine populations in different European countries.BMC Res Notes 5:190.

Caruso C, Modesto P, Bertolini S, Peletto S, Acutis PL, Dondo A, Robetto S, Mignone W, Orusa R, Ru G, Masoero L, 2015. Serological and virological survey of hepatitis E virus in wild boar populations in northwestern Italy: detection of HEV subtypes $3 \mathrm{e}$ and $3 \mathrm{f}$. Arch Viro1 60:153-60.

Caruso C, Peletto S, Rosamilia A, Modesto P, Chiavacci L, Sona B, Balsamelli F, Ghisetti V, Acutis PL, Pezzoni G, Brocchi E, Vitale N, Masoero L, 2017. Hepatitis E virus: a cross-sectional serological and virological study in pigs and humans at zoonotic risk within a highdensity pig farming area. Transbound Emerg Dis 64:1443-53.

Chihara TS, 1978. An Introduction to Orthogonal Polynomials. Gordon and Breach, New York.

De Sabato L, Ostanello F, De Grossi L, Marcario A, Franzetti B, Monini M, Di Bartolo I, 2018a. Molecular survey of $\mathrm{HEV}$ infection in wild boar population in Italy. Transbound Emerg Dis 65:1749-56.

De Sabato L, Vaccari G, Lemey P, Amoroso MG, Fusco G, Ianiro G, Di Bartolo I, 2018b. Phylogenetic analysis of two genotype 3 hepatitis $\mathrm{E}$ viruses from wild boar, Italy. Virus Genes 54:812-7.

Di Bartolo I, Martelli F, Inglese N, Pourshaban M, Caprioli A, Ostanello F, Ruggeri FM, 2008. Widespread diffusion of genotype 3 hepatitis $\mathrm{E}$ virus 
among farming swine in Northern Italy. Vet Microbiol 132:47-55.

Di Bartolo I, Diez-Valcarce M, Vasickova P, Kralik P, Hernandez M, Angeloni G, Ostanello F, Bouwknegt M, RodriguezLazaro D, Pavlik I, Ruggeri FM, 2012. Hepatitis $\mathrm{E}$ virus in pork production chain in Czech Republic, Italy, and Spain, 2010. Emerg Infect Dis 18:12829.

Di Bartolo I, Angeloni G, Ponterio E, Ostanello F, Ruggeri FM, 2015. Detection of hepatitis E virus in pork liver sausages. Int $\mathrm{J}$ Food Microbiol 193:29-33.

Di Bartolo I, Ponterio E, Angeloni G, Morandi F, Ostanello F, Nicoloso S, Ruggeri FM, 2017. Presence of hepatitis $\mathrm{E}$ virus in a red deer (Cervus elaphus) population in Central Italy. Transbound Emerg Dis 64:137-43.

Di Pasquale S, De Santis P, La Rosa G, Di Domenico K, Iaconelli, M, Micarelli G, Martini E, Bilei S, De Medici D, Suffredini E, 2019. Quantification and genetic diversity of Hepatitis E virus in wild boar (Sus scrofa) hunted for domestic consumption in Central Italy. Food Microbiol 82:194-201.

Doceul V, Bagdassarian E, Demange A, Pavio, N, 2016. Zoonotic hepatitis E virus: classification, animal reservoirs and transmission routes. Viruses 8:270.

European Food Safety Authority, 2017. Scientific Opinion on the public health risks associated with hepatitis $\mathrm{E}$ virus (HEV) as a food-borne pathogen. EFSA J 5:4886.

Farshadpour F, Taherkhani S, Taherkhani R, 2018. Hepatitis E virus infection during pregnancy: The overlooked cause of maternal and fetal mortality. Infect Disord Drug Targets https://doi.org/10.2174/1871526518666 180530075523

Garbuglia AR, Scognamiglio P, Petrosillo N, Mastroianni CM, Sordillo P, Gentile, D, La Scala P, Girardi E, Capobianchi MR, 2013. Hepatitis E virus genotype 4 outbreak, Italy, 2011. Emerg Infect Dis 19:110-14.

Johne R, Trojnar E, Filter M, Hofmann J, 2016. Thermal stability of hepatitis E virus as estimated by a cell culture method. Appl Environ Microbiol 82:4225-31.
Jothikumar N, Cromeans TL, Robertson BH, Meng XJ, Hill VR, 2006. A broadly reactive one-step real-time RT-PCR assay for rapid and sensitive detection of hepatitis E virus. J Virol Methods 131:65-71.

Kasorndorkbua C, Opriessnig T, Huang FF, Guenette DK, Thomas PJ, Meng X-J, Halbur PG, 2005. Infectious swine hepatitis $\mathrm{E}$ virus is present in pig manure storage facilities on United States farms, but evidence of water contamination is lacking. Appl Environ Microbiol 71:7831-7.

Kukielka D, Rodriguez-Prieto V, Vicente J, Sánchez-Vizcaíno JM, 2016. Constant hepatitis $\mathrm{E}$ virus (HEV) circulation in wild boar and red deer in Spain: an increasing concern source of HEV zoonotic transmission. Transbound Emerg Dis 63:e360-8.

ISO 15216-1:2017. Retrieved June 26, 2019, from ISO website: http://www. iso.org/cms/render/live/en/sites/isoorg/ contents/data/standard/06/56/65681.ht $\mathrm{ml}$

Mazzei M, Nardini R, Verin R, Forzan M, Poi A, Tolari F, 2015. Serologic and molecular survey for hepatitis $\mathrm{E}$ virus in wild boar (Sus scrofa) in Central Italy. New Microbes New Infect 7:41-7.

Pavio N, Doceul V, Bagdassarian E, Johne $\mathrm{R}, 2017$. Recent knowledge on hepatitis $\mathrm{E}$ virus in Suidae reservoirs and transmission routes to human. Vet Res 48:78.

Porea D, Anita A, Demange A, Raileanu C, Oslobanu Ludu L, Anita D, Savuta G, Pavio N, 2018. Molecular detection of hepatitis $\mathrm{E}$ virus in wild boar population in eastern Romania. Transbound Emerg Dis 65:527-33.

Rivero-Juarez A, Frias M, MartinezPeinado A, Risalde MA, RodriguezCano D, Camacho A, García-Bocanegra I, Cuenca-Lopez F, GomezVillamandos JC, Rivero A, 2017. Familial hepatitis E outbreak linked to wild boar meat consumption. Zoonoses Public Health 64:561-5.

Romanò L, Paladini S, Tagliacarne C, Canuti M, Bianchi S, Zanetti AR, 2011. Hepatitis E in Italy: a long-term prospective study. J Hepatol 54:34-40.

Rutjes SA, Lodder-Verschoor F, Lodder WJ, van der Giessen J, Reesink H, Bouwknegt M, de Roda Husman AM,
2010. Seroprevalence and molecular detection of hepatitis $\mathrm{E}$ virus in wild boar and red deer in The Netherlands. J Virol Methods 168:197-206.

Saez-Royuela C, Gomariz C, Telleria JL, 1989. Age determination of European wild boar (Sus scrofa). Wildl Soc Bull 17: 326-9.

Salines M, Andraud M, Rose N, 2017. From the epidemiology of hepatitis $\mathrm{E}$ virus (HEV) within the swine reservoir to public health risk mitigation strategies: a comprehensive review. Vet Res 48:31.

Serracca L, Battistini R, Rossini I, Mignone W, Peletto S, Boin C, Pistone G, Ercolini R, Ercolini C, 2015. Molecular investigation on the presence of hepatitis $\mathrm{E}$ virus $(\mathrm{HEV})$ in wild game in North-Western Italy. Food Environ Virol 7:206-12.

Sonoda H, Abe M, Sugimoto T, Sato Y, Bando M, Fukui E, Mizuo H, Takahashi M, Nishizawa T, Okamoto H, 2004. Prevalence of hepatitis E virus (HEV) infection in wild boars and deer and genetic identification of a genotype 3 HEV from a boar in Japan. J Clin Microbiol 42:5371-4.

Spancerniene U, Grigas J, Buitkuviene J, Zymantiene J, Juozaitiene V, Stankeviciute M, Razukevicius D, Zienius D, Stankevicius A, 2018. Prevalence and phylogenetic analysis of hepatitis E virus in pigs, wild boars, roe deer, red deer and moose in Lithuania. Acta Vet Scand 60:13.

Sridhar S, Teng JLL, Chiu T-H, Lau SKP, Woo PCY, 2017. Hepatitis E virus genotypes and evolution: emergence of camel hepatitis E variants. Int J Mol Sci 18:869.

Tei S, Kitajima N, Takahashi K, Mishiro S, 2003. Zoonotic transmission of hepatitis $\mathrm{E}$ virus from deer to human beings. Lancet 362:371-3.

Venables WN, Ripley BD, 2002. Modern Applied Statistics with S. Springer. New York.

Wenzel JJ, Preiss J, Schemmerer M, Huber B, Plentz A, Jilg W, 2011. Detection of hepatitis $\mathrm{E}$ virus (HEV) from porcine livers in Southeastern Germany and high sequence homology to human HEV isolates. J Clin Virol 52:50-4. 